Open Access

\title{
Shocks in food availability and intra- household resources allocation: evidence on children nutrition outcomes in Ethiopia
}

\author{
Gebremeskel Berhane Tesfay ${ }^{1,2^{*}}$ (1) and Babatunde Abidoye ${ }^{1,3}$
}

* Correspondence:
tbgmeskel@gmail.com
'Department of Agricultural
Economics, Extension and Rural
Development, University of Pretoria,
Pretoria, South Africa
${ }^{2}$ Mekelle University, Ethiopia, 451,
Mekelle University, Mekelle, Ethiopia
Full list of author information is
available at the end of the article

* Correspondence: tbgmeskel@gmail.com Economics, Extension and Rura Development, University of Pretoria, Pretoria, South Africa

Full list of author information is

available at the end of the article

\begin{abstract}
This paper examines the intra-gender nutrition outcome both with and without the presence of household level shock using Living Standards Measurement StudyIntegrated Survey (LSMS) panel data in Ethiopia. We used a mixed-effect estimation strategy to analyze how parents' gender preference affects resource allocation between boys and girls, and nutrition outcomes. We used a gender dummy and found that child gender dummy interaction with household level shock index variables does not have a significant effect on child nutrition. The results indicate that nutrition equality could be due to (1) the girls' biological bodily development that causes differences in trouble tolerance such that the girls' nutrition remains the same as that of boys and (2) the boys' physical exercises which cause weight loss such that it brings their nutrition down making it equal to that of the girls'. The results suggest the need for energy food supplementation for boys and a need for equal care for both girls and boys.
\end{abstract}

Keywords: Nutrition bias, Gender preference, Mixed-effects model, Resources, Shock index

JEL classification: 4: D - Microeconomics, 9: I - Health, Education, and Welfare, 17: Q - Agricultural and Natural Resource Economics

\section{Introduction}

Many of the intra-household child gender welfare studies using human capital investment show significant inequality between boys and girls (Quisumbing and Maluccio, 2000; Ejrnæs and Pörtner, 2004; Fafchamps et al. 2009; Behrman et al. 1982). Other welfare outcome studies based on child nutrition use anthropometric indicators as an alternative measurement technique to overcome the absence of child individual expenditure and child productivity information in many datasets.

Findings regarding intra-gender child nutrition inequality within a household show contextual evidence. Studies from South Asia indicate that a girl is worse off than a boy in nutrition outcomes (see for example, Behrman, 1988; Pal, 1999; Dancer et al. 2008) while in most Sub-Saharan African countries children are either equally malnourished or boys have less nutrition than girls (Garret and Ruel, 1999; Linnemayr et al. 2008; Quisumbing, 2003; Svedberg 1990). These findings indicate that child

(C) The Author(s). 2019 Open Access This article is distributed under the terms of the Creative Commons Attribution 4.0 International License (http://creativecommons.org/licenses/by/4.0/), which permits unrestricted use, distribution, and reproduction in any medium, provided you give appropriate credit to the original author(s) and the source, provide a link to the Creative Commons license, and indicate if changes were made. 
gender is found to be a determining factor in the intra-gender children nutrients allocation (see for example, Koohi-Kamali, 2008).

In the intra-gender resources allocation, the decision is mainly done by parents where child gender preference influence is the reason for the per capita human capital investment and health expenditure inequality between children's sex within the household. Parents' child gender preference refers to the attitude that parents give values to their kids on the basis of cultural and religious traditions and community norms, shaping individual attitudes and behavior (Behrman et al. 1982; Hank and Kohler, 2000; Clark, 2000; Rahman and Rao, 2004).

\section{Ethiopian context}

Family structure in rural Ethiopia is a typical institution with an approximately family size of $5 ; 46 \%$ of the population is under 15 years of age category (CSA 2007). According to the Ethiopian Population and Housing Census (2007) report, population by sex shows $50.5 \%$ and $49.5 \%$ male and female respectively.

Similar to other developing countries, per capita human capital investment and per capita health expenditure studies confirm pro-boy child gender bias in Ethiopia (Quisumbing and Maluccio, 2000; Quisumbing, 2003; Dercon and Singh, 2013; Rose and Al-Samarrai, 2001).

The child's expected benefits from human capital investment and cultural factors are determinants of gender biases (Jayachandran, 2014; Branisa et al. 2013; Asadullah, 2006). These inequalities are due to biases on female's reproductive decision, economic, educational, aspirations and self-efficacy, and social roles in a community.

Despite the wide advocacy and belief of the existence of bias against girls, anthropometric indicators $\left(z\right.$-score $\left.{ }^{1}\right)$ contradict the previous pro-boy bias evidence in Ethiopia.

A review study by Svedberg (1990) in more than 50 different datasets from Sub-Saharan African countries indicates minor bias towards girls. Another study by Marcoux (2002) in developing countries, including Ethiopia, indicates that boys fare worse than girls by anthropometric indicators. Results by Christiansen and Alderman (2004) also confirm these earlier findings. Later, child nutritional status study by Dercon and Singh (2013) in four countries (Ethiopia, India, Peru, and Vietnam) also shows a significant pro-girl gap in all of the countries.

Ethiopian Demographic and Health Survey (EDHS) 2011's report using height-for-age of children under age 5 shows that $44 \%$ are stunting of which $21 \%$ are severely stunted: in rural area, children are more stunted (46\%) versus urban area (32\%). The prevalence of stunting increases with age. Using weight-for-height, $10 \%$ of children under age 5 are wasting while $3 \%$ of them are severely wasting.

Likewise, nutritional outcome using weight-for-age indicates $29 \%$ of children under the age of 5 are underweight where $9 \%$ of them are severely underweight. To sum up, the results from EDHS survey in Ethiopia reveals that Ethiopian children under the age of 5 are stunted, wasting, and underweight of whom boys are worse off than girls in all the nutritional outcomes.

Thus far, we have seen two contradicting empirical evidence in a sense that in the one hand, literature on the per capita expenditure analysis show that boys are more favored than girls (Quisumbing and Maluccio, 2000; Quisumbing, 2003; Dercon and 
Singh, 2013; Rose and Al-Samarrai, 2001). On the other hand, the anthropometric indicators show that girls receive more nutrition than boys (Tarekegn et al. 2014). This conflicting evidence using these two excellent welfare predictors (i.e., per capita expenditure and nutrition measured using anthropometric indicators) is ambiguous and invites crucial follow-up questions on how and why nutrition outcomes are biased towards girls while per capita resource allocation are biased towards boys within a household.

The purpose of this paper, therefore, is to examine whether the effect of parents' child gender preference on child nutrition is unbiased and consistent across all children in the household.

Given scarce resources, families are expected to optimally allocate resources based on various factors such as return on child human capital investment and child gender preference. Similarly, household's optimization problem during shock risks takes a bit more different form of allocation decisions than during normal situations. Families may rationalize allocation by diverting resources from the less productive to relatively better productive members of the household (Morduch, 1995; Fafchamps et al. 1998). In the child's case, productivity cannot be a discriminatory variable for resource allocation between children, particularly for kids under 5 years old because it is difficult to determine child labor market wage. It is the parent's child gender preference if it exists that affects nutrient allocation between boys and girls. For instance, mothers could breastfeed longer time for boys than for girls at which breastfeeding duration is positively correlated with child nutrition.

Here, the decision is made at the household level while the decision outcome is at the individual level exhibiting hierarchical influences. As to the best of our knowledge, there is no hierarchical examination of this type of linkage between parents' decision versus child nutrition outcomes which exists at different levels in the hierarchy.

The nobility of this paper is that it examines the hierarchical effect of parents' allocation decision on child nutrition. Anthropometric indicators using the Ethiopian Living Standard Measurement Study (LSMS) dataset is used to address the questions of intra-child nutrition outcomes inequality between boys and girls in the study area.

The result of the mixed-effect estimation using hierarchical panel dataset in this work shows the non-existence of gender bias in nutrition between boys and girls both with and without household level shock index. Our result is inconsistent with the empirical findings on resource allocation and nutrition bias in Ethiopia.

The inter-class variance of clusters, between boys and girls group, shows a disparity between genders. The inter-class correlation coefficient (ICC) is between 0 and 1 suggesting that the nutrition equality might be due to (1) girls' biological bodily development difference so that difference in trouble tolerance keeps their nutrition the same as boys; and (2) boys' physical exercises which causes weight loss so that their nutrition is negatively affected.

The remainder of the paper is organized as follows: "The data" section is about describing the data. The "Model and empirical strategy" section discusses the theoretical model and empirical estimation strategy we applied. In the "Variable identification" section, we identify our variables of interest. The "Results and discussion" section discusses the results of the mixed-effect estimation model. Here, we complement our results by using $t$ test mean comparison of breastfeeding between boys and girls while the "Conclusions" section concludes our findings. 


\section{The data}

We used the Living Standards Measurement Study-Integrated Survey on Agriculture (LSMS-ISA) collected by Ethiopian Central Statistical Agency and the World Bank in two waves in Ethiopia. The first and second survey rounds were conducted in 2011/ 2012 and 2013/2014 respectively. We used these two round dataset (i.e., we exclude the third round dataset) for two reasons. One is that we started the work earlier than the third round dataset is freely available. The second reason is the fact that our focus of analysis is on children less than 5 years old; we choose to use the follow-up anthropometric information of a particular child who is in the less than 5 years age range in the two successive rounds.

According to the survey's Basic Information Document of LSMS survey, the Ethiopian Rural Socioeconomic Survey (ERSS) sample is drawn from a population frame that includes all rural and small-town areas of Ethiopia except for three zones of Afar Region and six zones of Somali Region.

The survey encompasses nine regions and one federal city administration (i.e., Diredawa); 69 zones are randomly drawn from these survey areas where 290 rural EAs $^{2}$ and 43 small-town EAs in total 333 EAs are included. Accordingly, 3969 households are randomly selected from the EAs.

Our interest is an individual-level welfare outcome variable (i.e., anthropometric indicators), as dependent variable, in reference to World Health Organization (WHO) standards used to calculate the $z$-score of child nutrition under five.

$>$ The $z$-score, welfare indicator at child level, is the outcome variable taken as a good proxy for child welfare so it is used to examine the welfare sharing among children within the household. We exclude the biologically implausible results of the $z$-score (dropped $z$-score results which are greater or equal to the absolute value of 6). For the purpose of examining the behavior of resources/nutrient allocation between genders, from the 3969 households, 1428 children are included in the regression after excluding children who do not have at least a sister or a brother of age below 5 years in the household.

Table 1 presents the descriptive statistics of the sample weight-for-age $z$-score, length/ height-for-age $z$-score, and weight-for-length/height $z$-score for children under consideration.

Looking at the weight-for-age $z$-score, $26 \%$ of the boys are underweight while the percentage rate for girls who are underweight is less than 25 (see Table 2).

In terms of height-for-age $z$-score, close to $44 \%$ of the boys and $40 \%$ of the girls are stunted. Yet, girls slightly fare better in nutrition than boys (see Table 2). Similarly, in Table 2, weight-for-length/height $z$-score shows that both boys and girls are wasting close to $10 \%$.

According to the World Health Organization (WHO, 1995), if population prevalence of malnutrition (i.e., for $\%$ of children $<60$ months years old) below $-2 z$-scores is between 25 and 29\%, then the degree of prevalence is high where EDHS report in 2011 confirms the high degree of prevalence in Ethiopia.

\section{Model and empirical strategy}

\section{The model}

Nutrition outcome differences between girls and boys can be attributed to differences in nutrient inputs in the health production function which in turn can be due to 
Table 1 Summary statistics of height-for-age, weight-for-age, and weight-for-height z-scores by sex

\begin{tabular}{llllllllllll}
\hline By sex & z-score & $N$ & Mean & SD & p5 & p10 & p25 & p50 & p75 & p95 & p99 \\
\hline Male & waz06 & 880 & -1.190 & 1.247 & -3.16 & -2.775 & -2.04 & -1.2 & -0.38 & 0.74 & 2.06 \\
& haz06 & 880 & -1.588 & 1.845 & -4.575 & -3.835 & -2.71 & -1.735 & -0.55 & 1.76 & 3.72 \\
& whz06 & 880 & -0.431 & 1.349 & -2.7 & -1.99 & -1.21 & -0.45 & 0.41 & 1.77 & 3.08 \\
\multirow{2}{*}{ Female } & waz06 & 548 & -1.143 & 1.300 & -3.34 & -2.79 & -1.985 & -1.16 & -0.24 & 0.82 & 2.26 \\
& haz06 & 548 & -1.498 & 1.941 & -4.58 & -3.91 & -2.81 & -1.525 & -0.46 & 1.84 & 4.4 \\
& whz06 & 548 & -0.386 & 1.360 & -2.61 & -1.99 & -1.215 & -0.41 & 0.46 & 1.89 & 2.96 \\
\multirow{2}{*}{ Total } & waz06 & 1428 & -1.172 & 1.267 & -3.25 & -2.78 & -2.02 & -1.18 & -0.34 & 0.8 & 2.11 \\
& haz06 & 1428 & -1.553 & 1.882 & -4.58 & -3.86 & -2.745 & -1.655 & -0.49 & 1.78 & 4.1 \\
& Whz06 & 1428 & -0.414 & 1.353 & -2.67 & -1.99 & -1.21 & -0.44 & 0.43 & 1.82 & 3.05 \\
\hline
\end{tabular}

Source: Author's statistical summary from the LSMS data for children $z$-score under 5 years, 2017

waz06, haz06, and whz06 are dependent variables which represent weight-for-age, height-for-age, and weight for height $z$-scores respectively

familial child gender preferences. Unlike the unitary model by Becker (1965), the collective model, nutrients allocation analysis, neither assumes homogenous parental preferences nor incorporates individual preferences into a single household utility function; it assumes a stable decision process which gives Pareto-efficient allocation within a household. Each Pareto frontier associates with various decision procedures connecting different sets of individuals' weight (Chiappori, 1997). Few works using this approach confirm that there is a bias towards girls' nutrition in a sense that Pareto weights are biased between boys and girls (Dercon and Pramela, 2000; Quisumbing, 2003; Duflo, 2000; Haddad and Hoddinott, 1994; Thomas, 1990).

To state the theoretical explanation of intra-children resource allocation, let $H_{i t}$ be nutrition outcomes of child $i$ at time $t$. The child health production function is dependent on the set of inputs denoted as " $P$ " which includes nutrient consumption, mother and father's time for childcare which also is dependent on observable/unobservable characteristics of the child (such as age, intimacy, and gender), and other household and community level variables. We present the household utility maximization problem as a function of child nutrition as follows:

$$
\max U\left(\mathrm{H}_{i t}\left(c_{i t}\right), \chi_{i t}\right)
$$

where $c_{i t}$ represents child $i$ 's consumption of goods and home-produced child health inputs and nutrients; $X_{i t}$ represents parent's consumption and household characteristics such as parent's education level, community level covariates such as access to

Table 2 Malnutrition statistics from the Ethiopian LSMS dataset

\begin{tabular}{lllllll}
\hline Variables & Female & & \multicolumn{3}{l}{ Male } \\
& N & Mean & SD & N & Mean & SD \\
\hline Wasting & 548 & 0.097 & 0.297 & 880 & 0.099 & 0.299 \\
Stunting & 548 & 0.403 & 0.491 & 880 & 0.433 & 0.496 \\
Underweight & 548 & 0.243 & 0.429 & 880 & 0.261 & 0.440 \\
\hline
\end{tabular}

Source: Authors' own summary from the LSMS dataset in Ethiopia, 2017 
the road. Health outcome of a child, $\mathrm{H}_{i t}$, is dependent on the child's nutrient intakes and other inputs which in turn are influenced by the parent's child gender preference and an aggregate household level environmental risk. Here, we assume every change in wealth of the household has an equal effect on nutrition of all household members. Then, we can put the relationship of child's nutrient consumption versus child gender preference and aggregate household environmental risks as

$$
c_{i t}\left(\phi_{i}, \theta_{t}\right)
$$

where $\phi_{i}$ and $\theta_{t}$ represent parent's child gender preference at all time, and an aggregate household level environmental risk index respectively. Both $\phi_{i}$ and $\theta_{t}$ are household level effects to child nutrition outcomes (i.e., individual level). Here, the nutrient inputs decision factors are likely to be different between child genders. In addition to the altruistic behavior of the household members, we assume that parents are the only allocation decision-makers so only the parent's preference is incorporated in the household utility function. Putting (1) as the weighted sum of parent's utility, it gives the following algebraic expression:

$$
\operatorname{Max} U_{t}=\omega_{i} U_{f t}\left(C_{f t}, \mathrm{H}_{i t}\right)+\left(1-\omega_{i}\right) U_{m t}\left(C_{m t}, \mathrm{H}_{i t}\right)
$$

Based on the cooperative optimization framework, parents (mother and father) agree to assign welfare weight level to the individuals in the household. We changed $f$ and $m$, subscripts which represent the father's and mother's consumption to $i$ just to include consumption of every individual member in the household. Therefore, Eq. (3) can again be restated as

$$
\max _{\left\{c_{i t}\right\}} \sum_{i=1}^{I} \omega_{i} U_{t}\left(C_{i t}\left(\phi_{i}, \theta_{t}\right), \mathrm{H}_{i t}\right)
$$

Subject

$$
C_{t}\left(\phi_{i}, \theta_{t}\right)=\sum_{i=1}^{I} C_{i t}\left(\phi_{i}, \theta_{t}\right) \leq \sum_{i=1}^{I} y_{i t}\left(\theta_{t}\right) \leq Y_{t}\left(\theta_{t}\right), \quad c_{i t}\left(\theta_{t}\right) \geq 0 \forall \theta_{t} \text { and } t
$$

and $0 \leq t \leq T$ is mother and father's available time devoted to childcare.

$C_{t}\left(\phi_{i}, \theta_{t}\right)$ is the aggregate consumption given the aggregate household level shock index, $\theta_{t}$, and child gender preferences, $\phi . C_{i t}$ is the individual consumption and nutrient consumption in kids' case. ${ }^{3}$ The aggregate consumption, $C_{t}\left(\phi_{i}, \theta_{t}\right)$, is the summation of all individual consumptions which is less or equal to the household disposable income ${ }^{4} Y_{t}$.

The non-negative value of $\omega_{i}$ is the Pareto weight, assumed to be consistent over time, allotted to individual members by the social planner so that resource is allocated based on the weight given to boys and girls (Browning and Chiappori 1998). Our concavity assumptions $U^{\prime}\left(\mathrm{H}_{i t}\right)>0$ and $U^{\prime \prime}\left(\mathrm{H}_{i t}\right)<0$ show that the utility function is an increasing function. 
Applying the Lagrange multiplier technique to Equation (4) with respect to $C_{i t}\left(\phi_{i}, \theta_{t}\right)$ and with the fact that summation of the pooled household income is greater or equal to the sum of household consumption as is in Equation (5):

$$
\sum_{i=1}^{I} y_{i t}\left(\theta_{t}\right) \geq \sum_{i=1}^{I} C_{t}\left(\theta_{t}\right)
$$

then, the marginal utility function is

$$
\omega_{i} U_{i}^{\prime}\left(C_{i t}\left(\phi_{i}, \theta_{t}\right), \mathrm{H}_{i t}\right)=\lambda\left(\theta_{t}\right)
$$

which after some derivation steps, it gives

$$
\frac{U_{i}^{\prime}\left(C_{i t}\left(\phi_{i}, \theta_{t}\right), \mathrm{H}_{i t}\right)}{U_{j}^{\prime}\left(C_{j t}\left(\phi_{i}, \theta_{t}\right), \mathrm{H}_{i t}\right)}=\frac{\omega_{j}}{\omega_{i}}
$$

Equation (8) the is parent's optimal level of utility obtained from the welfare outcomes of two individuals in the household which indicates that Equation (8) holds true if there is no bias in resource allocation.

Of interest here is the nutrition of non-working age group of children. As we have noted earlier, the nutrition achievements of children, in terms of $z$-score, in the same household can vary due to influences by unmeasured parents' characteristics such as child gender preference on resource allocation.

\section{Estimation strategy}

The structure of LSMS dataset in Ethiopia is a hierarchical type where individual child information is nested within the parents', and the household is, in turn, nested within the environmental shock that happened to the household. Our variable of interest, child nutrition outcome variable, is at an individual level, level 1; parents are at level 2; environmental shocks to the household ${ }^{5}$ are at level 3. In other terms, child nutrition achievements are influenced both by child's unobserved heterogeneity at an individual level, unobserved parents' preference heterogeneity on resources allocation at household level, and household level environmental shocks hieratically. Our hierarchical model for panel dataset is known as repeated measures or growth-curve model (Gelman and Hill, 2007; Balov, 2016; StataCorp L. P, 2013). Dropping the panel time subscript for convenience, let us present a simple repeated measures model (or growth-curve model) which allows both intercept and slope-coefficient to vary as (Raudenbush and Bryk, 2002):

$$
H_{0 p s}=\beta_{i p s}+\beta_{1 p s} g_{i p s}+\varepsilon_{i p s}
$$

where $i, p$, and $s$ represent individual, parents at level 2, and shock variables at level 3 respectively. $H_{i p s}, g_{i p s}$, and $\varepsilon_{i p s}$ denote nutrition outcomes of individual, $i$, individual covariates at level 1 , and idiosyncratic error respectively. $\beta_{1 p s}$ is the slope coefficient for variable $g_{i p s}$, a level 1 covariate. We are assuming that the constant term, $\beta_{i p s}$, randomly varies across units as a function of some level $2, x_{p}$ and level $3, k_{s}$ factors; these factors include household level and shock events variables. $\varepsilon_{i p s}$ is the idiosyncratic error term.

The model in (9) accounts for any possible heterogeneity associated with $p$ and $s$. In what follows from Equation (10) to (13), we explain how the random variation of the 
constant term across units that exists due to the effect of some higher-level factors. The intercept and slope at level 1 model in (9) vary between children depending on factors in level 2 presented as below

$$
\begin{aligned}
& \beta_{o p s}=\alpha_{00 s}+\alpha_{01} x_{1 p s}+u_{0 p s} \\
& \beta_{1 p s}=\alpha_{10 s}
\end{aligned}
$$

In the same way, intercepts in the level 2 models, $\beta_{o p s}$ and $\beta_{1 p s}$, vary between households according to the following level 3 models

$$
\begin{aligned}
& \alpha_{00 s}=\gamma_{000}+\gamma_{001} k_{1 s}+\ldots+\gamma_{005} k_{5 s}+v_{0 s} \\
& \alpha_{10 s}=\gamma_{100}+\gamma_{101} k_{1 s}+\ldots+\gamma_{105} k_{5 s}
\end{aligned}
$$

Substituting (12) and (13) into (10) and (11), respectively, and then substituting (10) and (11) in to (9) gives

$$
\begin{aligned}
H_{i p s}= & \left(\gamma_{000}+\gamma_{001} k_{1 s}+\ldots+\gamma_{005} k_{5 s}+v_{0 s}\right)+\left(\alpha_{01} x_{1 p s}+u_{0 p s}\right)+ \\
& \left(\gamma_{100}+\gamma_{101} k_{1 s}+\ldots+\gamma_{105} k_{5 s}\right) g_{i p s}+\varepsilon_{i p s}
\end{aligned}
$$

Rearranging the reduced-form model in (14), we get

$$
\begin{aligned}
H_{i p s}=\gamma_{000} & +\gamma_{001} k_{1 s}+\ldots+\gamma_{005} k_{5 s}+\gamma_{100} g_{i p s}+\gamma_{101} k_{1 s} g_{i p s}+\ldots+\gamma_{105} k_{5 s} g_{i p s} \\
& +\alpha_{01} x_{1 p s}+v_{0 s}+u_{0 p s}+\varepsilon_{i p s}
\end{aligned}
$$

where $v_{0 s}$ is the random intercept at level 3 while $u_{0 p s}$ is the random intercept at level 2 , and together with the idiosyncratic error at level $1, \varepsilon_{i p s}$ estimates the random effect part of (15) while the remaining is the fixed-effect part of it. $\gamma_{000}$ is the constant intercept and $\gamma_{001}, \gamma_{001}, \ldots$, and $\gamma_{005}$ represent slope coefficient that shows the correlation between the child nutrition outcome, $H_{i p s}$ and level 3 shocks, $k_{s}$. Similarly, $\gamma_{101}, \gamma_{102}$, $\ldots$, and $\gamma_{105}$ are slope coefficients for the interaction variables of the covariates at level $1, g_{i p s}$ and level 3 shocks, $k_{s}$ while $\gamma_{100}$ is a slope which measures the relationship between the outcome variable and covariates at level 1 . Here, we assume that $v_{0 s}, u_{0 p s}$, and $\varepsilon_{i p s}$ have 0 mean and constant variance.

Our hypothesis here is that parent's resources allocation and an aggregate shock to the household observed at levels 2 and 3 respectively have a biased effect on a child's nutritional outcome. Mixed-effect model for panel dataset technique is appropriate to estimate these hierarchical effects on a child's nutrition outcomes (Steenbergen and Jones 2002; Diez-Roux 2000). The multilevel analysis in (15) therefore starts first by estimating the fixed-effect part, then the random-effect part. The fixed effects are estimated directly, and the coefficients are similar to the standard regression coefficients while the random effects are summarized according to their variances and covariance (Raudenbush and Bryk, 2002; Castellano et al. 2014; Rabe-Hesketh et al. 2000).

The motivation is to identify whether family resource allocations are biased against gender and to estimate family allocation behavior with the existence of household level shocks.

Shock variables can be considered as an intervention to the decision-making process and are treated at a level 3/the highest level in the regression. All the household level variables are included at level 2 . 
Gender is a variable included as an identity identifier in our regression to check if there is any cluster nutrition variation between boys and girls. The inter-class correlation coefficient tells about the correlation of the observations between clusters in a sense that if the inter-class correlation which is calculated using the standard deviation of constant and level 1 residual approaches 0 , we should not use the grouping/clustering by gender at level 1 rather it is better to estimate simple regression; if the inter-class calculation result is close to 1 , then there is no variance between a boy and a girl to explain at level 1; they are the same. If the calculated inter-class is between 0 and 1 , this confirms that there is variance to explain due to the individual heterogeneity.

\section{Variable identification}

In Table 3, predictors comprising individual, household, and community-level variables are described. As it is noted above, nutrition is one of the excellent welfare indicators and therefore we used it to examine our hypothesis which deals with welfare allocation bias between genders.

Child welfare outcomes are child nutrition measured by the anthropometric indicators, namely, weight-for-age $z$-score (waz06), length/height-for-age $z$-score (haz06), and weight-for-length/height $z$-score (whz06). We used two waves' panel data, and we

Table 3 Variables included in the mixed-effects estimation model

\begin{tabular}{|c|c|c|c|c|c|}
\hline \multirow[t]{2}{*}{ Variables } & \multirow{2}{*}{$\begin{array}{l}(1) \\
\text { Mean }\end{array}$} & \multirow{2}{*}{$\begin{array}{l}(2) \\
S D\end{array}$} & \multirow{2}{*}{$\begin{array}{l}\text { (3) } \\
n\end{array}$} & \multirow{2}{*}{$\begin{array}{l}\text { (4) } \\
\text { Min }\end{array}$} & \multirow{2}{*}{$\begin{array}{l}\text { (5) } \\
\text { Max }\end{array}$} \\
\hline & & & & & \\
\hline Household size & 7.550 & 1.873 & 1.873 & 2 & 16 \\
\hline Number of meals that were shared over the past 7 days & 0.527 & 1.809 & 1.809 & 0 & 21 \\
\hline How many rooms & 1.834 & 1.074 & 1.074 & 0 & 9 \\
\hline Age of a child in months & 36.76 & 14.41 & 14.41 & 4.107 & 60 \\
\hline Number of sisters & 3.417 & 1.974 & 1.974 & 1 & 14 \\
\hline Breastfeeding duration in months & 7.102 & 11.21 & 11.21 & 0 & 48 \\
\hline Region & 2.326 & 1.330 & 1.330 & N/A & N/A \\
\hline Mother's education linked to a child & 0.404 & 0.664 & 0.664 & N/A & N/A \\
\hline Mother's hours spent on collecting firewood & 0.692 & 1.334 & 1.334 & 0 & 14 \\
\hline Mother's hours spent in agric activity in the last 7 days? & 24.90 & 22.86 & 22.86 & 0 & 96 \\
\hline $\mathrm{HH}$ distance in $(\mathrm{km})$ to nearest major road & 16.71 & 22.03 & 22.03 & 0 & 240.9 \\
\hline Plot distance in $(\mathrm{km})$ to $\mathrm{HH}$ & 1.619 & 6.911 & 6.911 & 0 & 80.20 \\
\hline 1 if medical aid, 0 otherwise & 0.186 & 0.389 & 0.389 & 0 & 1 \\
\hline Yes if credit over the past 12 months, 0 otherwise & 0.284 & 0.451 & 0.451 & 0 & 1 \\
\hline Ecological zone & 5.269 & 1.750 & 1.750 & N/A & N/A \\
\hline Male dummy, one if male, 0 otherwise & 0.616 & 0.486 & 0.486 & 0 & 1 \\
\hline 1 if spouse live together, 0 otherwise & 0.922 & 0.268 & 0.268 & 0 & 1 \\
\hline No. of days mother's work PSNP linked to kids & 0.936 & 8.187 & 8.187 & 0 & 180 \\
\hline Aggregate environmental shock index linked to individuals & 0.366 & 0.482 & 0.482 & 0 & 1 \\
\hline Length/height-for-age $z$-score & -1.553 & 1.882 & 1.882 & -6 & 5.300 \\
\hline Weight-for-age $z$-score & -1.172 & 1.267 & 1.267 & -5.400 & 3.040 \\
\hline Weight-for-length/height z-score & -0.414 & 1.353 & 1.353 & -4.730 & 4.730 \\
\hline
\end{tabular}

Source: Author's own summary estimation from LSMS dataset in Ethiopia, 2017; N/A is for not applicable PSNP stands for Productive Safety Net Program 
report the weight-for-age $z$-score (waz06) because it is a composite ${ }^{6}$ nutrition outcome indicator.

Child gender dummy is among the individual time-invariant variables of a child used for resource allocation comparison between children in a household.

During food scarcity, parents follow a pure investment strategy, exposing their more vulnerable children to greater malnutrition risk (see for example, Behrman, 1988; Chiappori, 1997; Dercon and Krishnan, 2000; Fafchamps, Kebede and Quisumbing, 2009; Thomas, 1990). Gender variable and its interaction with an aggregate household level shock index variable are included in the estimation to test if child welfare outcomes disparity exists. We used drought, flood, heavy rain, landslide, and crop damage variables to build our shock index ${ }^{7}$ variable. This aggregate environmental shock index is constructed to measure household-level resource-sharing behavior in the preceding season. The dummy responses for each of these shocks represents whether shocks occurred or not; 1 represents the occurrence of shock while 0 represents non-occurrence of shock. The sum of the dummies is averaged to the number of questions asked about the shocks. The occurrence of all the shocks is equal to 1 while the non-occurrence is 1 .

In child nutrition analysis, mother's education level is the common child nutrition predictor. Unlike father's time, ${ }^{8}$ mother's education level serves as a proxy for the cost of children because mothers are mainly responsible for rearing a child which is also known as the opportunity cost of their market wage.

Child breastfeeding duration in months, the age of a child in months, and medical aid or aid consultancy are also among the individual specific predictors included in the regression.

Dummy variable if spouses live together in the household is also included to see if a collective agreement on resource allocation differently affects more the welfare of different-sex children than the ones whose spouses do not live together.

We incorporate region variation variable which enables us to compare the child nutrition differences in different regions of the nation. Amhara, Oromia, Tigrai, SNNP, ${ }^{9}$ and "other ${ }^{10}$ regions" variables are included in our regression where Amhara Region is the reference category in our factor variable of the regional variation analysis.

Time devoted to child care is one of the excellent predictors of child nutrition and health where the distance to the main road and land/plot to the household competes mothers' time.

\section{Results and discussions}

Table 4 indicates the result of the mixed-effects estimation strategy of our hierarchical model. Nutrition outcomes (the $z$-scores) are estimated on the covariates. Regression results of weight-for-age $z$-score, length/height-for-age $z$-score, and weight-for-length/ height $z$-score are in the first, second, and third columns respectively.

We interpret the anthropometric measurements of nutrition, a good indicator of intra-household resource allocation (Horton, 1988), using weight-for-age $z$-scores because it is a composite index of height-for-age and weight-for-height. The first is an index showing stunting; an indicator of linear growth retardation and cumulative growth deficits in children. Stunting is the result of failure to receive adequate nutrition over a long period of time and recurrent and chronic illness. The second is an index 
Table 4 Mixed-effect estimation result without shocks

\begin{tabular}{|c|c|c|c|}
\hline \multirow[t]{2}{*}{ Variables } & $(1)$ & $(2)$ & (3) \\
\hline & $\begin{array}{l}\text { Weight-for-age } \\
z \text {-score }\end{array}$ & $\begin{array}{l}\text { Length/height- } \\
\text { for-age } z \text {-score }\end{array}$ & $\begin{array}{l}\text { Weight-for-length/ } \\
\text { height } z \text {-score }\end{array}$ \\
\hline \multirow[t]{2}{*}{ Age of a child in months } & $-0.008^{* * *}$ & -0.004 & $-0.006^{* *}$ \\
\hline & $(0.00)$ & $(0.00)$ & $(0.00)$ \\
\hline \multirow[t]{2}{*}{ Breastfeeding duration in months } & $0.007^{* * *}$ & $0.013^{* * *}$ & -0.000 \\
\hline & $(0.00)$ & $(0.00)$ & $(0.00)$ \\
\hline \multirow[t]{2}{*}{ Male dummy } & 0.004 & -0.002 & -0.038 \\
\hline & $(0.08)$ & $(0.12)$ & $(0.08)$ \\
\hline \multirow[t]{2}{*}{ Household size } & 0.006 & 0.033 & -0.009 \\
\hline & $(0.02)$ & $(0.04)$ & $(0.03)$ \\
\hline \multirow[t]{2}{*}{ Number of sisters } & -0.031 & $-0.071^{* *}$ & 0.017 \\
\hline & $(0.02)$ & $(0.03)$ & $(0.02)$ \\
\hline \multirow{2}{*}{$\begin{array}{l}\text { What was the total number of meals that were shared } \\
\text { over the past } 7 \text { days with }\end{array}$} & 0.020 & 0.002 & 0.026 \\
\hline & $(0.02)$ & $(0.03)$ & $(0.02)$ \\
\hline \multirow[t]{2}{*}{$\mathrm{HH}$ distance in $(\mathrm{km})$ to nearest major road } & 0.003 & $0.007^{* *}$ & -0.000 \\
\hline & $(0.00)$ & $(0.00)$ & $(0.00)$ \\
\hline \multirow[t]{2}{*}{ Plot distance in $(\mathrm{km})$ to $\mathrm{HH}$} & $-0.009^{*}$ & $-0.015^{*}$ & -0.002 \\
\hline & $(0.01)$ & $(0.01)$ & $(0.01)$ \\
\hline \multirow[t]{2}{*}{1 if medical aid, 0 otherwise } & -0.123 & 0.053 & $-0.232^{* *}$ \\
\hline & $(0.08)$ & $(0.12)$ & $(0.09)$ \\
\hline \multirow[t]{2}{*}{ Mother's hours spent on collecting firewood } & 0.009 & 0.006 & 0.011 \\
\hline & $(0.03)$ & $(0.04)$ & $(0.03)$ \\
\hline \multirow[t]{2}{*}{ How many rooms } & $0.154^{* * *}$ & $0.185^{* * *}$ & 0.059 \\
\hline & $(0.03)$ & $(0.05)$ & $(0.04)$ \\
\hline \multirow[t]{2}{*}{ Yes if credit over the past 12 months, 0 otherwise } & -0.025 & -0.069 & 0.019 \\
\hline & $(0.08)$ & $(0.11)$ & $(0.08)$ \\
\hline \multirow[t]{2}{*}{1 if spouse live together, 0 otherwise } & 0.094 & -0.088 & 0.156 \\
\hline & $(0.14)$ & $(0.21)$ & $(0.15)$ \\
\hline \multirow[t]{2}{*}{ Mother's hours spent in agric activity in the last 7 days? } & 0.002 & 0.004 & -0.001 \\
\hline & $(0.00)$ & $(0.00)$ & $(0.00)$ \\
\hline \multirow[t]{2}{*}{ Mother's hours spent working at PSNP within 12 months } & -0.003 & -0.008 & 0.002 \\
\hline & $(0.00)$ & $(0.01)$ & $(0.00)$ \\
\hline \multirow[t]{2}{*}{ Max_primary } & $0.275^{* * *}$ & $0.340^{* * *}$ & 0.089 \\
\hline & $(0.09)$ & $(0.13)$ & $(0.09)$ \\
\hline \multirow[t]{2}{*}{ Junior } & 0.312 & 0.017 & $0.417^{*}$ \\
\hline & $(0.24)$ & $(0.34)$ & $(0.24)$ \\
\hline \multirow[t]{2}{*}{ Senior and above } & $0.718^{* * *}$ & $0.672^{*}$ & $0.481^{*}$ \\
\hline & $(0.25)$ & $(0.37)$ & $(0.26)$ \\
\hline \multirow[t]{2}{*}{ Tigrai } & -0.192 & -0.333 & -0.053 \\
\hline & $(0.18)$ & $(0.25)$ & $(0.18)$ \\
\hline \multirow[t]{2}{*}{ Oromo } & $0.356^{* * *}$ & $0.465^{* *}$ & 0.143 \\
\hline & $(0.13)$ & $(0.19)$ & $(0.13)$ \\
\hline \multirow[t]{2}{*}{ SNNP } & 0.210 & 0.081 & $0.244^{*}$ \\
\hline & $(0.14)$ & $(0.20)$ & $(0.14)$ \\
\hline Other regions & $0.375^{* *}$ & $0.420^{* *}$ & 0.190 \\
\hline
\end{tabular}


Table 4 Mixed-effect estimation result without shocks (Continued)

\begin{tabular}{|c|c|c|c|}
\hline \multirow[t]{2}{*}{ Variables } & $(1)$ & $(2)$ & (3) \\
\hline & $\begin{array}{l}\text { Weight-for-age } \\
z \text {-score }\end{array}$ & $\begin{array}{l}\text { Length/height- } \\
\text { for-age } z \text {-score }\end{array}$ & $\begin{array}{l}\text { Weight-for-length/ } \\
\text { height } z \text {-score }\end{array}$ \\
\hline & $(0.15)$ & $(0.21)$ & $(0.15)$ \\
\hline \multirow[t]{2}{*}{ Tropic-warm/semiarid } & -0.037 & $-0.920^{*}$ & $0.767^{* *}$ \\
\hline & $(0.38)$ & $(0.55)$ & $(0.39)$ \\
\hline \multirow[t]{2}{*}{ Tropic-warm/subhumid } & 0.156 & -0.459 & $0.686^{*}$ \\
\hline & $(0.40)$ & $(0.58)$ & $(0.41)$ \\
\hline \multirow[t]{2}{*}{ Tropic-warm/humid } & 1.492 & 0.471 & 1.902 \\
\hline & $(1.27)$ & $(1.89)$ & $(1.40)$ \\
\hline \multirow[t]{2}{*}{ Tropic-cool/arid } & -0.391 & -1.207 & 0.422 \\
\hline & $(0.74)$ & $(1.08)$ & $(0.78)$ \\
\hline \multirow[t]{2}{*}{ Tropic-cool/semiarid } & 0.218 & -0.797 & $1.093^{* * *}$ \\
\hline & $(0.37)$ & $(0.54)$ & $(0.38)$ \\
\hline \multirow[t]{2}{*}{ Tropic-cool/subhumid } & 0.263 & -0.850 & $1.166^{* * *}$ \\
\hline & $(0.38)$ & $(0.55)$ & $(0.39)$ \\
\hline \multirow[t]{2}{*}{ Tropic-cool/humid } & 0.067 & $-0.977^{*}$ & $1.002^{* *}$ \\
\hline & $(0.39)$ & $(0.57)$ & $(0.40)$ \\
\hline \multirow[t]{2}{*}{ Constant } & -1.824 & -1.446 & -1.598 \\
\hline & $(0.46)$ & $(0.66)$ & $(0.47)$ \\
\hline Number of observations & 1427 & 1427 & 1427 \\
\hline \multirow[t]{2}{*}{ SD (idcoleg1) } & -0.300 & -0.036 & -0.503 \\
\hline & $(0.06)$ & $(0.07)$ & $(0.10)$ \\
\hline \multirow[t]{2}{*}{ SD (idclase1) } & -1.066 & -0.913 & -11.752 \\
\hline & $(0.32)$ & $(0.56)$ & $(505.76)$ \\
\hline \multirow[t]{2}{*}{ SD (residual) } & -0.072 & 0.406 & 0.166 \\
\hline & $(0.03)$ & $(0.03)$ & $(0.03)$ \\
\hline \multicolumn{4}{|l|}{ ICC-L1 } \\
\hline \multicolumn{4}{|l|}{ ICC-L2 } \\
\hline$-2 \mathrm{LL}$ & -2242.363 & -2834.628 & -2410.102 \\
\hline df & 29.0 & 29.0 & 29.0 \\
\hline
\end{tabular}

Source: Authors' estimation result from LSMS data in Ethiopia, standard errors in parentheses, no. of observation $=1427$, ${ }^{* * *} p<0.01,{ }^{* *} p<0.05,{ }^{*} p<0.1$

indicating wasting; this measures body mass in relation to body height or length and shows current- or short-run nutritional status of a child.

As it can be seen in Table 4, male dummy confirms that the weights ratio equality in Equation (8) is stable. The hypothesis for the equal coefficient for the individual time-invariant variable, male dummy, is not rejected. This goes in contradiction with the findings by Svedberg (1990), Christiansen and Alderman (2004), and Peterman et al. (2014) that provide evidence on the presence of parents' gender bias on resource allocation.

The boy's nutrition, the standard deviation of nutrition ( $z$-score) as compared to World Health Organization standard reference population, is not affected by our male dummy variable. We find this result very interesting because, unlike the literature 
findings using the per capita analysis, it shows that the optimal resource allocation is not violated by gender.

Table 5 shows the result of the same model where nutrition outcomes are model's dependent variables which are estimated on the covariates with interaction. Similarly, results of weight-for-age $z$-score, length/height-for-age $z$-score, and weight-for-length/ height $z$-score are in the first, second, and third columns respectively. The results with variable interactions in Table 5 confirm the non-existence of significant gender bias effect on nutrition outcome. Gender dummy that interacted with aggregate household level shock index variable does not show any significant effect on nutrition except its negative sign of the coefficients which hint on that shocks negatively affect the nutrition of both sexes.

Three possible reasons for the ambiguity due to the inconsistency of our result: one might be due to the data structure used for analysis. All of the empirical findings we have seen thus far consider that their data structure is a non-clustered/non-nested dataset. In practice, individual nutrition information is clustered at the individual level while resource allocation decision-making is done at the higher level, household level. That is, the individual-level variable is nested at the higher-level actions, household-level actions, which require hierarchical modeling and hierarchical estimation technique such that it captures the inter-cluster differences between boys and girls. Therefore, our hierarchical model analysis adjusts for unmeasured heterogeneity that exists in panel data studies. Hierarchical model estimation offers substantial benefits over classical, non-hierarchical approaches (Feller and Gelman, 2015).

The second possible reason can also be biological differences in trouble tolerance between boys and girls, i.e., given less than adequate food supply, girls tend to cope better with a shortage of food than boys from the standpoint of their bodily development (see for example, Marcoux, 2002). In the presence of resource gap and allocation disparity between boys and girls, boy's nutrition is expected to be better off than girls, if girls cannot cope with troubles better than boys. Excellent evidence for the existence of differences between boy and girl groups is the inter-class correlation coefficient ${ }^{11}$ (ICC) of our hierarchical/mixed-effects model. ICC result is in between 0 and 1 (that is, 0.46 between individuals and 0.63 on average) which indicates a difference in variance between boys and girls due to the biological bodily development so it is a reason for nutrition equality while there is allocation disparity.

The third argument is that boys at this age do more physical exercises relative to girls (see for example, Timmons et al. 2007; Timmons et al. 2012). That is, boys spend more energy than girls such that the boys' body weight during their preschool age makes the boys' nutrition equal to the girls' nutrition despite allocation disparity. In Table 5, during bad times, while boys still exercise/spend energy more than girls, the result shows an insignificant negative gender effect on nutrition with an unequal coefficient which hints on the existence of a slight pro-boy resource allocation bias.

Our conclusion is that the equality in nutrition is only due to differences in coping troubles and child's physical activities.

Now let us turn to other child nutrition predictors. Consistent with the literature on nutrition (Behrman et al. 1982; Behrman, 1988; Horton, 1988), child age indicates an inverse relationship with nutrition; as age increases, a child's nutrition declines, while breastfeeding duration in months shows a positive correlation with nutrition. The 
Table 5 Mixed-effect estimation result with interaction/with shocks

\begin{tabular}{|c|c|c|c|}
\hline \multirow[t]{2}{*}{ Variables } & (1) & (2) & (3) \\
\hline & $\begin{array}{l}\text { Weight-for-age } \\
z \text {-score }\end{array}$ & $\begin{array}{l}\text { Length/height-for- } \\
\text { age } z \text {-score }\end{array}$ & $\begin{array}{l}\text { Weight-for-length/ } \\
\text { height } z \text {-score }\end{array}$ \\
\hline \multirow[t]{2}{*}{ Age of a child in months } & $-0.008^{* * *}$ & -0.004 & $-0.006^{* *}$ \\
\hline & $(0.00)$ & $(0.00)$ & $(0.00)$ \\
\hline \multirow[t]{2}{*}{ Breastfeeding duration in months } & 0.007 & $0.013^{* * *}$ & -0.000 \\
\hline & $(0.00)$ & $(0.00)$ & $(0.00)$ \\
\hline \multirow[t]{2}{*}{ Male dummy } & 0.021 & 0.067 & -0.058 \\
\hline & $(0.10)$ & $(0.14)$ & $(0.10)$ \\
\hline \multirow[t]{2}{*}{ Household size } & 0.007 & 0.034 & -0.009 \\
\hline & $(0.02)$ & $(0.04)$ & $(0.03)$ \\
\hline \multirow[t]{2}{*}{ Number of sisters } & -0.031 & $-0.070^{* *}$ & 0.016 \\
\hline & $(0.02)$ & $(0.03)$ & $(0.02)$ \\
\hline \multirow[t]{2}{*}{ Number of meals shared over the past 7 days } & 0.019 & 0.000 & 0.026 \\
\hline & $(0.02)$ & $(0.03)$ & $(0.02)$ \\
\hline \multirow[t]{2}{*}{ Female \# shock_index } & -0.045 & -0.016 & -0.032 \\
\hline & $(0.13)$ & $(0.19)$ & $(0.14)$ \\
\hline \multirow[t]{2}{*}{ Male \# shock_index } & -0.084 & -0.194 & 0.024 \\
\hline & $(0.10)$ & $(0.15)$ & $(0.11)$ \\
\hline \multirow[t]{2}{*}{$\mathrm{HH}$ distance in $(\mathrm{km})$ to nearest major road } & 0.003 & $0.007^{* *}$ & -0.000 \\
\hline & $(0.00)$ & $(0.00)$ & $(0.00)$ \\
\hline \multirow[t]{2}{*}{ Plot distance in $(\mathrm{km})$ to $\mathrm{HH}$} & $-0.010^{*}$ & $-0.015^{*}$ & -0.002 \\
\hline & $(0.01)$ & $(0.01)$ & $(0.01)$ \\
\hline \multirow[t]{2}{*}{1 if medical aid, 0 otherwise } & -0.125 & 0.052 & $-0.232^{* *}$ \\
\hline & $(0.08)$ & $(0.12)$ & $(0.09)$ \\
\hline \multirow[t]{2}{*}{ Mother's hours spent on collecting firewood } & 0.010 & 0.006 & 0.011 \\
\hline & $(0.03)$ & $(0.04)$ & $(0.03)$ \\
\hline \multirow[t]{2}{*}{ How many rooms } & 0.153 & $0.184^{* * *}$ & 0.058 \\
\hline & $(0.03)$ & $(0.05)$ & $(0.04)$ \\
\hline \multirow[t]{2}{*}{ Yes if credit over the past 12 months, 0 otherwise } & -0.021 & -0.060 & 0.019 \\
\hline & $(0.08)$ & $(0.11)$ & $(0.08)$ \\
\hline \multirow[t]{2}{*}{1 if spouse live together, 0 otherwise } & 0.092 & -0.095 & 0.158 \\
\hline & $(0.14)$ & $(0.21)$ & $(0.15)$ \\
\hline \multirow{2}{*}{$\begin{array}{l}\text { Mother's hours spent in agric activity in the } \\
\text { last } 7 \text { days? }\end{array}$} & 0.002 & $0.005^{*}$ & -0.001 \\
\hline & $(0.00)$ & $(0.00)$ & $(0.00)$ \\
\hline \multirow{2}{*}{$\begin{array}{l}\text { Mother's hours spent working at PSNP within } \\
12 \text { months }\end{array}$} & -0.003 & -0.007 & 0.002 \\
\hline & $(0.00)$ & $(0.01)$ & $(0.00)$ \\
\hline \multirow[t]{2}{*}{ Max_primary edu } & $0.279^{* * *}$ & $0.349^{* * *}$ & 0.088 \\
\hline & $(0.09)$ & $(0.13)$ & $(0.09)$ \\
\hline \multirow[t]{2}{*}{ Junior level edu } & 0.317 & 0.019 & $0.420^{*}$ \\
\hline & $(0.24)$ & $(0.34)$ & $(0.24)$ \\
\hline \multirow[t]{2}{*}{ Senior and above level edu } & $0.711^{* *}$ & $0.663^{*}$ & $0.479^{*}$ \\
\hline & $(0.25)$ & $(0.37)$ & $(0.26)$ \\
\hline \multirow[t]{2}{*}{ Tigrai } & -0.212 & -0.366 & -0.053 \\
\hline & $(0.18)$ & $(0.26)$ & $(0.18)$ \\
\hline Oromo & $0.354^{* * *}$ & $0.466^{* *}$ & 0.141 \\
\hline
\end{tabular}


Table 5 Mixed-effect estimation result with interaction/with shocks (Continued)

\begin{tabular}{|c|c|c|c|}
\hline \multirow[t]{2}{*}{ Variables } & \multirow{2}{*}{$\begin{array}{l}\text { (1) } \\
\text { Weight-for-age } \\
z \text {-score }\end{array}$} & \multirow{2}{*}{$\begin{array}{l}\text { (2) } \\
\text { Length/height-for- } \\
\text { age } z \text {-score }\end{array}$} & \multirow{2}{*}{$\begin{array}{l}\text { (3) } \\
\text { Weight-for-length/ } \\
\text { height } z \text {-score }\end{array}$} \\
\hline & & & \\
\hline & $(0.13)$ & $(0.19)$ & $(0.13)$ \\
\hline \multirow[t]{2}{*}{ SNNP } & 0.233 & 0.127 & 0.241 \\
\hline & $(0.14)$ & $(0.21)$ & $(0.15)$ \\
\hline \multirow[t]{2}{*}{ Other regions } & $0.370^{* *}$ & $0.416^{* *}$ & 0.188 \\
\hline & $(0.15)$ & $(0.21)$ & $(0.15)$ \\
\hline \multirow[t]{2}{*}{ Tropic-warm/semiarid } & -0.023 & -0.891 & $0.764^{* *}$ \\
\hline & $(0.38)$ & $(0.55)$ & $(0.39)$ \\
\hline \multirow[t]{2}{*}{ Tropic-warm/subhumid } & 0.158 & -0.447 & $0.682^{*}$ \\
\hline & $(0.40)$ & $(0.58)$ & $(0.41)$ \\
\hline \multirow[t]{2}{*}{ Tropic-warm/humid } & 1.469 & 0.470 & 1.883 \\
\hline & $(1.27)$ & (1.89) & $(1.40)$ \\
\hline \multirow[t]{2}{*}{ Tropic-cool/arid } & -0.370 & -1.182 & 0.428 \\
\hline & $(0.74)$ & $(1.08)$ & $(0.78)$ \\
\hline \multirow[t]{2}{*}{ Tropic-cool/semiarid } & 0.222 & -0.782 & $1.089^{* * *}$ \\
\hline & $(0.37)$ & $(0.54)$ & $(0.38)$ \\
\hline \multirow[t]{2}{*}{ Tropic-cool/subhumid } & 0.252 & -0.864 & $1.163^{* * *}$ \\
\hline & $(0.38)$ & $(0.55)$ & $(0.39)$ \\
\hline \multirow[t]{2}{*}{ Tropic-cool/humid } & 0.045 & $-1.013^{*}$ & $1.002^{* *}$ \\
\hline & $(0.39)$ & $(0.57)$ & $(0.41)$ \\
\hline \multirow[t]{2}{*}{ Constant } & -1.817 & -1.469 & -1.580 \\
\hline & $(0.46)$ & $(0.67)$ & $(0.48)$ \\
\hline Number of observations & 1427 & 1427 & 1427 \\
\hline \multirow[t]{2}{*}{ SD (idcoleg1) } & -0.302 & -0.041 & -0.503 \\
\hline & $(0.06)$ & $(0.08)$ & $(0.10)$ \\
\hline \multirow[t]{2}{*}{ SD (idclase1) } & -1.066 & -0.914 & -12.287 \\
\hline & $(0.32)$ & $(0.57)$ & $(854.06)$ \\
\hline \multirow[t]{2}{*}{ SD (residual) } & -0.071 & 0.406 & 0.166 \\
\hline & $(0.03)$ & $(0.03)$ & $(0.03)$ \\
\hline \multicolumn{4}{|l|}{ ICC-L1 } \\
\hline \multicolumn{4}{|l|}{ ICC-L2 } \\
\hline$-2 \mathrm{LL}$ & -2242.016 & -2833.798 & -2410.041 \\
\hline df & 31.0 & 31.0 & 31.0 \\
\hline
\end{tabular}

Source: Authors' estimation result from LSMS data in Ethiopia, standard errors in parentheses, *** $p<0.01$, ${ }^{* *} p<0.05,{ }^{*} p<0.1$

statistically negative significance of child age in months complements the argument that physical exercise can facilitate weight loss and affect nutrition.

Another evidence is the relationship between getting individual medical aid and child nutrition.

Unlike the expectation, these variables have an inverse relationship though statistically insignificantly correlated.

In normal circumstances, individuals who get medical aid and health consultancy are expected to be healthy and have more nutrition than the ones who do not. The explanation 
for the inverse relationship of these variables here can be the community practice; parents or guardians take children to health centers for medical aid/consulting after they get sick.

A value of 1 in our dummy most probably indicates that the child is suffering from an illness which implies that the child have less nutrition with a probable existence of endogeneity problem between illness and nutrition (Dercon and Krishnan, 2000).

Maternal education may have a bigger impact on child welfare distribution and nutrition. Our result on mothers' education level, a usual child's nutrition predictor, confirms that mothers with primary, secondary, and tertiary education level have a more positive significant effect on child's nutrition as compared to mothers with no education.

Mother's hours spent in fetching water and other agricultural activities show an insignificant negative effect on child's nutrition.

Area variation incorporated in our regression shows that a boy from Tigrai Region shows a more insignificant negative coefficient than a boy in Amhara Region (the reference category in our factor variable).

Compared to the Amhara Region, a boy being in Oromia has more nutrition than a boy in Amhara; the evidence is positive significant coefficient at $1 \%$ level of significance.

SNNP region variation is not a significant effect on nutrition while the coefficients for other regions ${ }^{12}$ show a positive correlation that a boy is better in nutrition than in Amhara Region.

We can conclude that a child who grows in Tigrai, a region located at the most northern part of the nation, usually associated with war front and drought-prone area, is less nourished than a child who grows in any other region of the nation.

Mom's participation in PSNP shows that an inverse effect on nutrition may be due to the composite income effect earned from different modality of PSNP participation ${ }^{13}$ (Quisumbing, 2003). According to Quisumbing (2003), the impact of PNSP on child nutrition depends on whether the household is the recipient of FD or FFW. Our dataset does not have participation modality information; therefore, we remain inconclusive about the result.

As expected, plot distance to the household in kilometers shows significant inverse correlation with nutrition.

A number of rooms owned by the household indicate positive significant correlation with nutrition. Most of the time, a number of rooms and household wealth are positively correlated implying that wealthy people own a large number of residence rooms. This correlation can also imply that children from wealthy households have relatively more nutrition than those from the poor households.

Household size, number of sisters, and number of meals share variables do not have a significant effect on nutrition. One possible reason for this might be the fact that children at this age are not supposed to share the burden of consequences of these variables.

Thus far, we discuss the determining factors of child nutrition with particular emphasis on the impact of parent's child gender preference on nutrition. Furthermore, the interaction of aggregate household level shock index and male dummy variables gives us a clue about the welfare allocation between genders within the household. In both cases, we tried to see if the unobserved parent's child gender preference affects a child's nutrition. 
Table 6 is $t$ test of child breastfeeding duration between boys and girls which compares children mean breastfeeding duration in months.

Like the slight median breastfeeding difference between boys and girls in the Ethiopian Demographic Survey (2011) report, the boys' median breastfeeding, in our case, is slightly greater (25.7 median breastfeeding) than girls' (24.8 median breastfeeding) which indicates small mean breastfeeding difference between boys and girls.

The $t$ test mean comparison result supports our justification for why resource allocation is biased towards boys although the study is about both boys' and girls' nutrition.

Taking breastfeeding duration as a proxy variable for welfare distribution among children in a household, the small mean deviation in breastfeeding duration in a month indicates that the social planner in the household allocates a bit biased towards boys' welfare weights.

By implication, male children to a female children welfare-weight ratio within the household would remain slightly unequal.

\section{Conclusions}

Children growth standards show that children born worldwide should grow in equal growth status regardless of where they were born. Adequate nutrition, environment, and health are the major determinants of child growth where child gender and ethnic origin are minor determinants. Nevertheless, many empirical studies on nutrition indicate that there are deviations when examined against the WHO 2006 growth standards and other standard cut-offs.

Similar to the EDHS (2011) report, this paper, using the Ethiopian LSMS dataset collected in 2011/2012 and 2013/14 confirms that close to half of Ethiopian children up to 5 years old are below the WHO 2006 growth standards. Out of 880 boys, 43\% of them are stunted while for $40 \%$ of the 548 sample of girls are stunted. Furthermore, $26 \%$ of boys are underweight relative to $24 \%$ for girls.

Results from the mixed-effect estimation depicted in Tables 4 and 5 show unbiased nutrition outcome with gender. At a glance, our results with and without imposing the aggregate household level shock index variable indicate that there is no nutrition bias between genders.

Empirical evidence based on different measurement techniques, namely, using per capita human capital investment and per capita health expenditure and anthropometric indicators do not show the same result. The per capita expenditure estimations show that resources allocation in a household is biased against girls. On the other hand, the empirical works using anthropometric indicators confirm the contrary. Many of them find that girls have more nutrition than boys. We find inconsistent evidence in this aspect. Our results indicate that boys and girls have equal nutrition. Our conclusion to

Table 6 t test mean comparison of breastfeeding duration in months

\begin{tabular}{lllll}
\hline Group & Obs & Mean & Std. error & SD \\
\hline Male & 880 & 7.280 & 0.385 & 11.425 \\
Female & 548 & 6.816 & 0.465 & 10.873 \\
Combined & 1428 & 7.102 & 0.297 & 11.212 \\
Difference & & 0.464 & 0.610 & \\
\hline
\end{tabular}

Source: Author's own summary from Ethiopian LSMS dataset, $\operatorname{Pr}(|T|>|t|)=0.4473$ 
this contradiction is deduced from the three possible scenarios we have explained above. The nutrition equality is due to differences in stress tolerance and physical exercises between boys and girls. Even though resource allocation is biased against girls, girls' bodily development enables them to tolerate stress such that their nutrition is equal to boys' during food shortage. Another scenario might be that, in this age group, boys exercise more than girls (Timmons et al. 2012). Therefore, boys' physical exercise reduces boys' body weight (i.e., it negatively affects the anthropometric indicators of a boy), compared to girls' body weight which in turn makes boys' have equal nutrition as girls even though boys get more resources than girls.

In bad times, had resource been allocated equally between genders while boys still exercise/lose body weight than girls, nutrition allocation (i.e., the anthropometric indicator) should definitely be in favor of girls. Therefore, in both good and bad time cases, our estimation result confirms that there is nutrition allocation bias against girls.

From a policy perspective, knowing the relative intra-household differences in nutrition for the different groups within the household is important. Therefore, what we have found is an evidence that boys at this age group spent more energy than girls, and girls are better in stress tolerance so all these compensations make nutrition equal while resource allocation is biased. Nutrition inequalities would remain large had resources allocation been not biased towards boys. Such resource allocation differences, while there is seemingly nutrition equality between boys and girls, can lead to short-run drawback (such as difference in vulnerability to disease) on boys' health and it may also lead to permanent effects and diminished health and education outcomes that may also be a reason for adulthood inequalities in the long run (see for instance, Alderman et al. 2006; Case and Paxson, 2006).

One concern on these findings is the household structure and bargaining power of decision-making process in the household. Bargaining power of decision-makers at the household level, particularly women's empowerment, plays a crucial role on food consumption allocation. Our next research interest is to see the effect of women's empowerment on the intra-gender child nutrition disparity within a household.

\section{Endnotes}

${ }^{1} z$-score in this case is child welfare measured by child nutrition where nutrition in turn is calculated using anthropometric indicators. It tells how many standard deviations child nutrition is from world health organization standard references for nutrition.

${ }^{2}$ EAs stands for enumeration areas

${ }^{3}$ Note that a small "c $c$ " in Equations (1) and (2) represents child nutrients and is assumed as the domain of $\mathrm{H}_{i t}$ from Equation (3) onwards.

${ }^{4}$ Here, the total disposable income consists of all incomes earned from different sources.

${ }^{5}$ We level child nutrition as level 1 because it is nested with the parents' decisions, i.e., individuals are nested within groups, and parents' decision is also nested in the shock event.

${ }^{6}$ "Weight-for-age is a composite index of height-for-age and weight-for-height. It takes both chronic and acute malnutrition into account. A child can be underweight 
for his/her age because he or she is stunted, wasted, or both. Children with weight-for-age below minus two standard deviations (-2SD) are classified as underweight. Children with weight-for-age below minus three standard deviations (-3SD) are considered severely underweight" (EDHS, 2011).

${ }^{7}$ Shock index is the summation of the dummies of these five environmental shocks, i.e., Shock index $=\frac{\sum_{5} X_{i}}{5}$ where $X_{i}$ are the shocks, $i=5$

${ }^{8}$ Father's education effect on nutrition is usually considered as pure income effect because relative to mothers, fathers are not involved to any great extent in the rearing of children.

${ }^{9}$ SNNP is an abbreviation for Southern Nations, Nationalities, and Peoples' region in Ethiopia

${ }^{10}$ Refers to Benshangulgumuz, Gambela, Deredawa, Harari, and Somali regions.

${ }^{11}$ Interclass correlation coefficient (ICC) is calculated as ICC $=\frac{\sigma_{u}^{2}}{\sigma_{u}^{2}+\sigma_{\varepsilon}^{2}}$ where $\sigma_{u}^{2}$ represents standard deviation of constant while $\sigma_{\varepsilon}^{2}$ represents standard deviation of residuals. "If the interclass correlation coefficient (ICC) approaches 0 then the grouping by gender is of no use, recommend to run a simple regression. If the IC approaches 1 then there is no variance to explain at the individual level, everybody is the same" (Torres-Reyna, 2010).

${ }^{12}$ Regions included in the "other regions variable" are Benshangulgumuz, Gambella, Dire-Dawa, Harari, and Somali regions.

${ }^{13}$ Food aids through PSNP participation modalities in Ethiopia are free distribution (FD) and food-for-work (FFW). According to Quisumbing (2003), FFW targets asset-poor households while FD does not depend on wealth though, most of the time, the recipients are less wealthy.

\section{Acknowledgements}

The authors are grateful for the Ph.D. fellowship fund by NORHED Project on Capacity Building for Climate Smart Natural Resource Management and Policy (CLISNARP). Authors are also thankful for the World Bank for the publicly available Living Standards Measurement Survey (LSMS) dataset in Ethiopia.

Funding

NORHED Project on Capacity Building for Climate Smart Natural Resource Management and Policy (CLISNARP) financed the Ph.D. program for the first author.

\section{Availability of data and materials}

Data and material are freely available, we used Living Standard Measurement Survey (LSMS) dataset, we will provide on request.

\section{Authors' contributions}

GT developed the empirical study concept and identified the gap in the literature. Both authors work closely. GT and BA work in formulating the research hypotheses, data analysis, and interpreting the findings. All authors read and approved the final manuscript.

Competing interests

The authors declare that they have no competing interests.

\section{Publisher's Note}

Springer Nature remains neutral with regard to jurisdictional claims in published maps and institutional affiliations.

\section{Author details}

${ }^{1}$ Department of Agricultural Economics, Extension and Rural Development, University of Pretoria, Pretoria, South Africa.

${ }^{2}$ Mekelle University, Ethiopia, 451, Mekelle University, Mekelle, Ethiopia. ${ }^{3}$ Yale University, New Haven, USA. 
Received: 21 January 2018 Accepted: 10 January 2019

Published online: 13 February 2019

\section{References}

Alderman H, Hoddinott J, Kinsey B (2006) Long term consequences of early childhood malnutrition. Oxf Econ Pap 58(3):450474

Asadullah MN (2006) Schools, Household, Risk, and Gender: Determinants of Child Schooling in Ethiopia

Balov N (2016, August) Bayesian hierarchical models in Stata. In 2016 Stata Conference (No. 30). Stata Users Group

Becker GS (1965) A theory of the allocation of time. Econ J:493-517

Behrman JR (1988) Intrahousehold allocation of nutrients in rural India: are boys favored? Do parents exhibit inequality aversion? Oxford Economic Papers 40(1):32-54

Behrman JR, Pollak RA, Taubman P (1982) Parental preferences and provision for progeny. J Polit Econ 90(1):52-73

Branisa B, Klasen S, Ziegler M (2013) Gender inequality in social institutions and gendered development outcomes. World Dev 45:252-268

Browning M, Chiappori PA (1998) Efficient intra-household allocations: a general characterization and empirical tests. Econometrica:1241-1278

Case A, Paxson C (2006) Children's health and social mobility. The Future of Children:151-173

Castellano KE, Rabe-Hesketh S, Skrondal A (2014) Composition, context, and endogeneity in school and teacher comparisons. J Educ Behav Stat 39(5):333-367

Central Statistical Agency (2007) Population and Housing of Ethiopia report

Chiappori PA (1997) Introducing household production in collective models of labor supply. J Polit Econ 105(1):191-209

Christiansen L, Alderman H (2004) Child malnutrition in Ethiopia: can maternal knowledge augment the role of income? Econ Dev Cult Chang 52(2):287-312

Clark S (2000) Son preference and sex composition of children: evidence from India. Demography 37(1):95-108

Dancer D, Rammohan A, Smith MD (2008) Infant mortality and child nutrition in Bangladesh. Health Econ 17(9):1015-1035

Dercon S, Krishnan P (2000) In sickness and in health: risk sharing within households in rural Ethiopia. J Polit Econ 108(4):688-727

Dercon S, Singh A (2013) From nutrition to aspirations and self-efficacy: gender bias over time among children in four countries. World Dev 45:31-50

Diez-Roux AV (2000) Multilevel analysis in public health research. Annu Rev Public Health 21(1):171-192

Duflo E (2000) Child health and household resources in South Africa: evidence from the old age pension program. Am Econ Rev 90(2):393-398

Ejrnæs M, Pörtner CC (2004) Birth order and the intrahousehold allocation of time and education. Rev Econ Stat 86(4):1008-1019 Ethiopia D.H.S (2011) Final report Central Statistical Agency Addis Ababa

Fafchamps M, Kebede B, Quisumbing AR (2009) Intrahousehold welfare in rural Ethiopia. Oxf Bull Econ Stat 71(4):567-599

Fafchamps M, Udry C, Czukas K (1998) Drought and saving in West Africa: are livestock a buffer stock? J Dev Econ 55(2):273305

Feller A, Gelman A (2015) Hierarchical models for causal effects. Emerging Trends in the Social and Behavioral Sciences: An Interdisciplinary, Searchable, and Linkable Resource

Garrett JL, Ruel MT (1999) Are determinants of rural and urban food security and nutritional status different? Some insights from Mozambique. World Dev 27(11):1955-1975

Gelman A, Hill J (2007) Data analysis using regression and multilevelhierarchical models (Vol. 1). Cambridge University Press, New York, NY, USA

Haddad L, Hoddinott J (1994) Women's income and boy-girl anthropometric status in the Côte d'Ivoire. World Dev 22(4): 543-553

Hank K, Kohler HP (2000) Gender preferences for children in Europe: empirical results from 17 FFS countries. Demogr Res 2 Horton S (1988) Birth order and child nutritional status: evidence from the Philippines. Econ Dev Cult Chang 36(2):341-354

Jayachandran S (2014) The roots of gender inequality in developing countries (No. w20380). National Bureau of Economic Research

Koohi-Kamali F (2008) Intrahousehold inequality and child gender bias in Ethiopia

Linnemayr S, Alderman H, Ka A (2008) Determinants of malnutrition in Senegal: individual, household, community variables, and their interaction. Economics \& Human Biology 6(2):252-263

Marcoux A (2002) Sex differentials in undernutrition: a look at survey evidence. Popul Dev Rev 28(2):275-284

Morduch J (1995) Income smoothing and consumption smoothing. The journal of economic perspectives 9(3):103-114

Pal S (1999) An analysis of childhood malnutrition in rural India: role of gender, income and other household characteristics. World Dev 27(7):1151-1171

Peterman A, Behrman JA, Quisumbing AR (2014) A review of empirical evidence on gender differences in nonland agricultural inputs, technology, and services in developing countries. In: Gender in Agriculture. Springer, Netherlands, pp 145-186

Quisumbing AR (2003) Food aid and child nutrition in rural Ethiopia. World Dev 31(7):1309-1324

Quisumbing AR, Maluccio JA (2000) Intrahousehold allocation and gender relations: new empirical evidence from four developing countries. International Food Policy Research Institute, Washington, DC

Rabe-Hesketh S, Pickles A, Taylor C (2000) Generalized linear latent and mixed models. Stata Tech Bull 53:47-57

Rahman L, Rao V (2004) The determinants of gender equity in India: examining Dyson and Moore's thesis with new data. Popul Dev Rev 30(2):239-268

Raudenbush SW, Bryk AS (2002) Hierarchical linear models: Applications and data analysis methods (Vol. 1). Sage

Rose P, Al-Samarrai S (2001) Household constraints on schooling by gender: empirical evidence from Ethiopia. Comp Educ Rev 45(1):36-63

StataCorp L. P (2013) Stata Multilevel mixed-effects Reference manual. College Station, TX: StataCorp LP

Steenbergen MR, Jones BS (2002) Modeling multilevel data structures. Am J Polit Sci:218-237

Svedberg P (1990) Undernutrition in sub-Saharan Africa: is there a gender bias? J Dev Stud 26(3):469-486

Tarekegn SM, Lieberman LS, Giedraitis V (2014) Determinants of maternal health service utilization in Ethiopia: analysis of the 2011 Ethiopian demographic and health survey. BMC pregnancy and childbirth 14(1):161 
Thomas D (1990) Intra-household resource allocation: an inferential approach. J Hum Resour:635-664

Timmons BW, LeBlanc AG, Carson V, Connor Gorber S, Dillman C, Janssen I et al (2012) Systematic review of physical activity and health in the early years (aged 0-4 years). Appl Physiol Nutr Metab 37(4):773-792

Timmons BW, Naylor PJ, Pfeiffer KA (2007) Physical activity in children of preschool age-amount and method? Applied physiology, nutrition, and metabolism= Physiologie appliquee, nutrition et metabolisme 32:S136-S149 Torres-Reyna O (2010) Multilevel analysis

World Health Organization (1995) Physical status: the use of and interpretation of anthropometry. Report of a WHO Expert Committee World Health Organization (2006) WHO child growth standards: length/height for age, weight-for-age, weight-for-length, weight-for-height and body mass index-for-age, methods and development. World Health Organization

Submit your manuscript to a SpringerOpen ${ }^{0}$ journal and benefit from:

- Convenient online submission

- Rigorous peer review

Open access: articles freely available online

High visibility within the field

- Retaining the copyright to your article 